CORRESPONDENCE

\title{
Response to: Is formal visual field testing essential prior to upper eyelid surgery in a post-COVID-19 era?
}

(c) The Author(s), under exclusive licence to The Royal College of Ophthalmologists 2021

Eye (2022) 36:1332; https://doi.org/10.1038/s41433-021-01639-2

\section{TO THE EDITOR:}

We read with great interest the paper by Theodorsson et al. [1]. We agree that formal visual field testing is unnecessary for determining whether surgical repair of ptosis is clinically appropriate within the resource-limitations of the NHS and would go further to suggest that photographic evidence may also be unwarranted.

We have previously highlighted the wide variation in CCG access policies for oculoplastic procedures, including ptosis, as well as the potential for healthcare inequalities and delays in treatment these can produce $[2,3]$. We identified $80 \%$ of policies restricting access to ptosis surgery required formal visual fieldtesting, $18 \%$ required photographs and $0.9 \%$ allowed either. However, only 3 CCGs waive visual field testing where MRD1 is 1 $\mathrm{mm}$ or less. Where qualifying field defects were quantified, $38 \%$ of CCGs stipulated restrictions to 120 degrees laterally, and 29\% 40 degrees vertically, appearing to draw on DVLA guidelines, but there was large variation [4]. Such wide variations regarding visual field and photography requirements highlights the lack of evidence-basis for their application and may have resulted from failing to engage experts in drafting access policies [2].

We recognise the implications of current infection control issues and agree that visual field-testing resources must be prioritised for patients with sight threatening conditions such as glaucoma. Furthermore, we would argue that clinical photographs also increase appointment duration, patient-staff contact and economic burden and may not be appropriate in the current pandemic. Clinicians have been forced to make prioritisation decisions during this pandemic with far wider implications than those regarding the functional impact of a patient's ptosis and should be trusted to interpret patients' histories and clinical findings, including MRD1 without requiring the consumption of additional scarce resources.

\author{
Samantha Vicki Hunt $\mathbb{D}^{1 凶}$ and Rebecca Ford (D) ${ }^{1}$ \\ ${ }^{1}$ University Hospitals Bristol and Weston NHS Foundation Trust, \\ Bristol Eye Hospital, England, UK. ${ }^{\bowtie}$ email: samanthahunt2@nhs.net
}

\section{REFERENCES}

1. Theodorsson $M$, Soare $C$, Vonica $O$, Sherafat $H$. et al. Is formal visual field testing essential prior to upper eyelid surgery in a post-COVID-19 era? Eye. 2021;35:1520-1. https://doi.org/10.1038/s41433-020-1103-x

2. Hunt SV, Ford R. Recognising the impact of local funding policies on clinical practice: an exploration of clinical commissioning group funding of oculoplastic procedures. Eye. 2020;1-2. https://doi.org/10.1038/s41433-020-01258-3

3. Hunt SV, Ford R. Clinical commissioning group funding of oculoplastic services- is there a postcode lottery? Br J Health Care Manag (in press).

4. Driver and Vehicle Licensing agency. Visual disorders: assessing fitness to drive. GOV.UK. 2021.https://www.gov.uk/guidance/visual-disorders-assessing-fitness-todrive (accessed 5 May 2021).

\section{COMPETING INTERESTS}

The authors declare no competing interests.

\section{ADDITIONAL INFORMATION}

Correspondence and requests for materials should be addressed to S.V.H.

Reprints and permission information is available at http://www.nature.com/ reprints

Publisher's note Springer Nature remains neutral with regard to jurisdictional claims in published maps and institutional affiliations. 